\title{
Partial-thickness corneal tissue restoration after a chemical burn
}

This article was published in the following Dove Press journal:

International Medical Case Reports Journal

6 April 2016

Number of times this article has been viewed

\section{Alessandro Galan \\ Anton Giulio Catania Giuseppe Lo Giudice}

San Paolo Ophthalmic Center, San Antonio Hospital, Padova, Italy
Correspondence: Anton Giulio Catania San Paolo Ophthalmic Center, San Antonio Hospital, Via Facciolati 7I, Padova 35 I 26, Italy

$\mathrm{Tel}+390498216729$

$\mathrm{Fax}+390498216448$

Email ag.catania@gmail.com
Purpose: We describe a case of full-thickness corneal restoration after an acute corneal burn with an acid agent.

Methods: A 32-year-old male reported painful discomfort, redness, photophobia, and a decrease in visual acuity in the left eye after a unilateral burn with an acid agent. Slit-lamp examination revealed massive corneal melting involving necrotic sequestrum of the entire corneal surface. Surgical approach was carried out in order to preserve residual ocular tissues.

Results: Extensive corneal-conjunctival layer curettage of the necrotic tissue was performed showing perfectly clear undamaged deep lamellar corneal layers. The patient underwent multilayered amniotic membrane transplantation and total capsular-conjunctival flap in order to preserve ocular tissue from further melting or corneal perforation. A complete and spontaneous "restitutio ad integrum" of the corneal layers was shown during the follow-up. The cornea was perfectly clear with restored normal anatomical architecture.

Conclusion: In this case, a spontaneous full-thickness corneal tissue restoration occurred after an acute chemical burn. Studies about the mechanisms whereby different cells interact and replicate within the stroma may unveil the biology behind corneal regeneration and transparency.

Keywords: amniotic membrane, chemical burn, corneal healing

\section{Introduction}

Ocular burns constitute true ocular emergencies, and both thermal and chemical burns represent potentially blinding ocular injuries. Recovery of ocular surface burns depends upon the causative agent and the extent of damage to corneal, limbal, and conjunctival tissues at the time of injury. ${ }^{1}$ Developments in the management of ocular surface burns, such as amniotic membrane transplantation (AMT), have been used in the treatment of several ophthalmic disorders and conditions. ${ }^{2}$ However, even amniotic membrane (AM) grafts, which work largely by providing a substrate for epithelial cells to grow on, fail when there are no surviving epithelial, conjunctival, or limbal cells. In this article, we report an unusual case of full-thickness corneal regeneration in a patient with an acute acid burn. This report adhered to the tenets of the Declaration of Helsinki.

\section{Case report}

A 32-year-old male reported painful discomfort, redness, photophobia, and a decrease in visual acuity in the left eye after a unilateral burn with ammonium defluoridate and sulfuric acid. The patient was referred to the Cornea Service of San Paolo Ophthalmic Center (San Antonio Hospital, Padova, Italy). The patient was initially treated with submit your manuscript | www.dovepress.com

Dovepress

http://dx.doi.org/10.2|47/IMCRJ.S99293
International Medical Case Reports Journal 2016:9 87-90 
irrigation of saline to normalize the ocular surface $\mathrm{pH}$, and for removal of remaining particulate matter, prophylactic topical antibiotics, lubricants, steroids, and cycloplegics were used. Three days after primary accident, slit-lamp examination revealed massive corneal involvement with an extensive necrotic/degenerative corneoconjunctival tissue covering the entire surface and obscuring both the iris details and anterior chamber. The entire limbus and conjunctiva were involved (Figure 1A). No Seidel's phenomenon was shown on slitlamp examination.

After an informed written consent was obtained, the patient underwent accurate surgical debridement (Video S1). The necrotic corneoconjunctival tissue was excised from the entire corneal surface under surgical microscopy. During this procedure, a clear and perfect corneal tissue was shown ( $\sim 90 \%$ of corneal stroma was removed by curettage, leaving Descemet's membrane clearly seen in the central area; Figure 1B). Multilayered AMT was performed in order to preserve the exposed corneal tissues and to stimulate both reepithelialization and regeneration of the corneal architecture. A sutureless AM was arranged in multiple layers so that the entire ocular surface was covered, as well as the peripheral corneal-limbal surface. AM patch was then covered by a full-thickness conjunctival flap, including Tenon's capsule. ${ }^{3}$ The rationale of this procedure was to control corneal inflammation and pain, as well as to ensure protection and healing efficacy. Penetrating keratoplasty was considered either as a surgical procedure at the time of flap removal or as a separate event in an eye with visual potential.

Postoperative treatment consisted of topical eyedrops (dexamethasone $0.15 \%$ and ofloxacin $0.3 \%$ ) four times daily. Steroids were slowly tapered, while topical antibiotics were discontinued after a 4-week follow up period. AM flap retraction occurred spontaneously, leaving the ocular surface free during the follow-up (4-5 months). The cornea appeared clear and 90\%-100\% corneal stromal thickness was regained (Figure 2A). Optical coherence tomography showed a central corneal thickness of $508 \mu \mathrm{m}$ measured at the apex of the corneal surface. To evaluate the changes in cell morphology in regenerated tissues, corneal epithelium was evaluated from the central area of regenerated cornea using confocal microscopy (Figure 2B). The flattened surface and smaller basal epithelial cells were normal in morphology and layer numbers also. Corneal nerve bundles regenerated in the corneal stroma. Anterior keratocytes and stroma were unevenly distributed, with bright nuclei and signs of opacity (Figure 2C). Best-corrected visual acuity was 20/40 OS.

The cornea remained transparent with complete clearing over the 12-month follow-up period. A residual peripheral
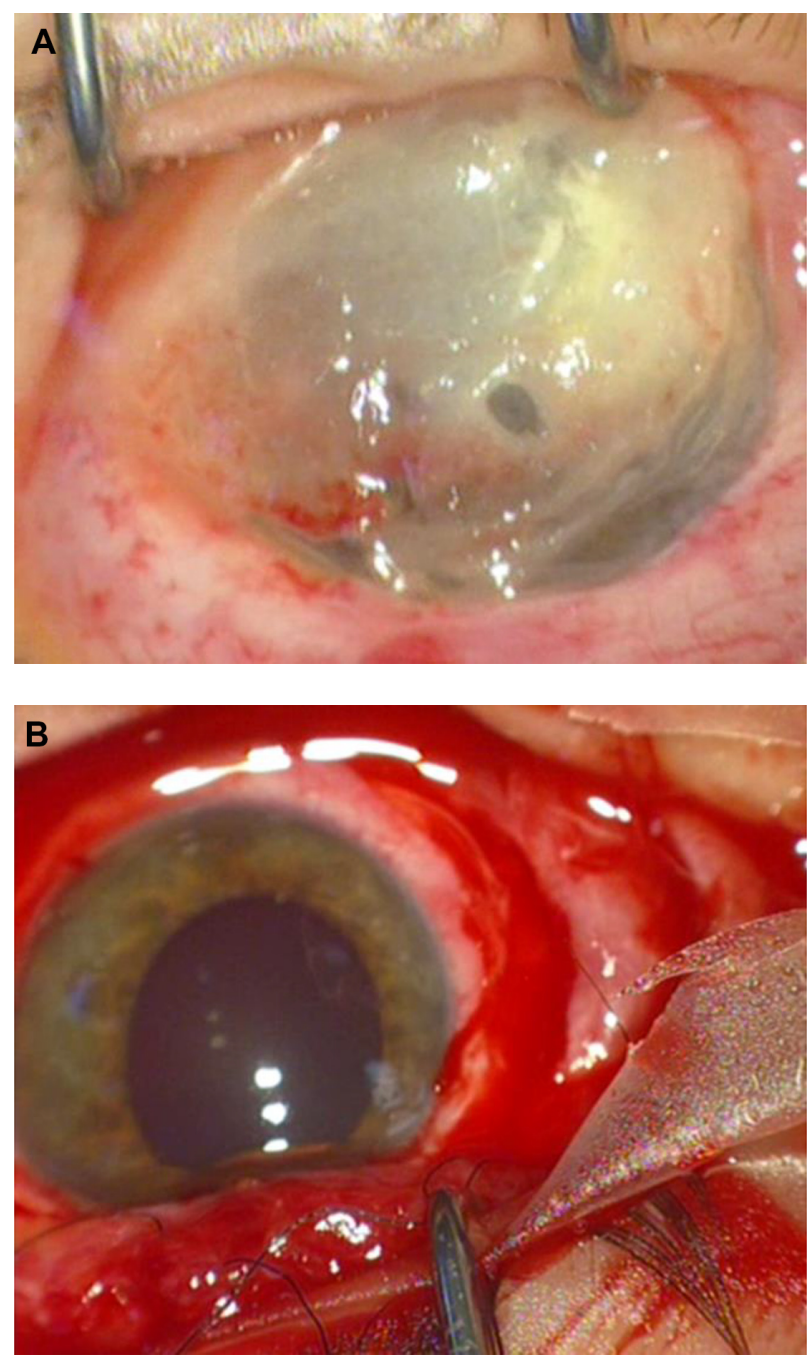

Figure I Ocular surface before and after necrotic tissue excision.

Notes: (A) Ocular surface 10 days after an acute burn. An extensive necrotic/ degenerative corneoconjunctival tissue covering the entire surface is shown. (B) Under surgery microscope, a perfectly clear normal Descemet's membrane was observed.

vascularized corneal pannus diffusion in three quadrants of the cornea, without involvement of the optic axis, was shown. There was a complete reepithelialization with no neovascularization or other ocular surface abnormality. A residual symblepharon confined to the upper fornix was also observed.

\section{Ethical approval}

A detailed explanation of the treatment was given to the patient, and informed written consent was obtained before any procedure. This protocol was approved by the institutional review board of the San Paolo Ophthalmic Center, San Antonio Hospital.

\section{Discussion}

Recovery of ocular surface burns depends upon the causative agent and the extent of damage to corneal, limbal, and 

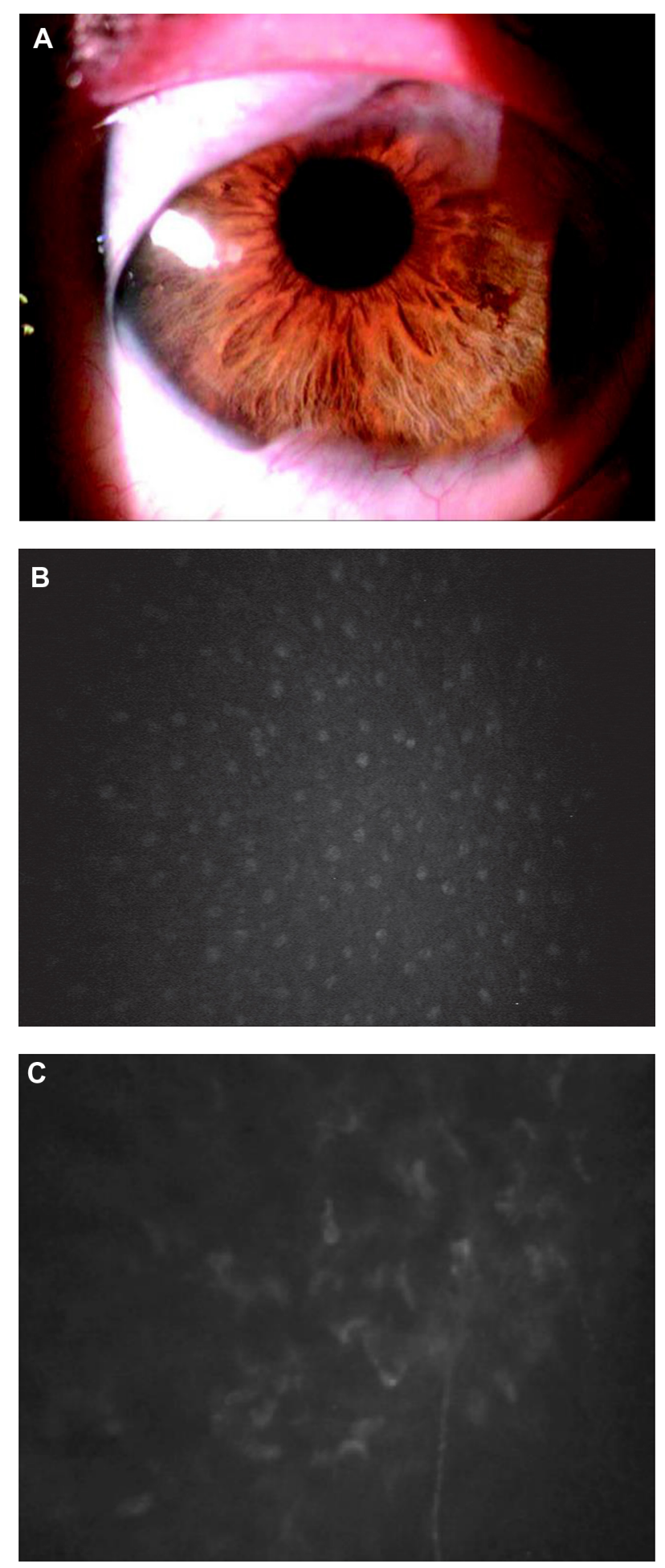

Figure 2 Postoperative evaluation by means of slit-lamp and corneal confocal microscopy.

Notes: (A) Postsurgery evaluation (4-5 months). On slit-lamp biomicroscopy, the cornea and anterior chamber were both clear with restored corneal stromal over the follow-up period. (B) Confocal microscopy shows epithelial and stromal regeneration with reinnervation. A normal corneal epithelium morphology with large superficial cells is seen in the regenerated epithelium. (C) Corneal nerve bundles regenerated in the corneal stroma. Anterior keratocytes and stroma were unevenly distributed, with bright nuclei and signs of opacity. (B and $\mathbf{C}$ ) Corneal confocal microscopy was performed using Confoscan 4.0 (Nidek, Gamogori, Japan), equipped with an Achroplan non-applanating 40x immersion objective lens (Zeiss, Oberkochen, Germany). The standard dimension of each image produced was $420 \times 315 \mu \mathrm{m}\left(\right.$ area $\left.=0.132 \mathrm{~mm}^{2}\right)$, with an optical section thickness of $5 \mu \mathrm{m}$. conjunctival tissues at the time of injury. ${ }^{1}$ Several procedures would be considered in order to manage such an event. Procedures including AMT, autolimbal transplantation, and allolimbal transplantation have been reported in several studies. ${ }^{2,45}$ Some of these describe a partial and/or complete recovery of the stroma in patients who underwent AMT for corneal perforation and point out that AMT might influence the proliferation and migration of neighboring keratocytes, leading to stromal substance synthesis. ${ }^{4,5} \mathrm{AM}$ undergoes subsequent progressive modification after integration because of the biological interactions that influence tissue healing and scar formation with incomplete clearing of the residual tissue, although a partial recovery of the AM tissue transparency, once integrated, is achieved. This limits any optical or visual benefits of stromal restoration.

We describe an unusual and complete restoration of the entire stromal thickness without reflectivity reduction in a patient exposed to acute burns caused by acid agents. We do not have a complete explanation to such a phenomenon. We hypothesize a remodeling of the stroma with new collagen formation and repopulating with corneal stroma-derived cells, fibroblasts, and myofibroblasts that layered down new collagen. Unknown trophic and regenerative factors might have induced mitotic effects on quiescent corneal keratocytes, which first underwent replication and then secreted normal corneal stroma components, including keratin sulfate and collagens (essential to build up new corneal stroma in a patient where only the Descemet's membrane was preserved). Because it is a well-established fact that corneal stroma has minimal or no regenerative properties (sporadic corneal stroma in human restoration is anecdotal), the observation that, in some animal models, the cornea can regenerate does have scientific significance. ${ }^{6}$ Indeed, we cannot also exclude the potential of human keratocytes to repopulate stromal tissue without scarring. ${ }^{7}$ Keratocytes might not conform to the classic definition of terminal differentiation, and at least some cells in the stroma may respond and regenerate transparent corneal tissue. ${ }^{?}$

Our report has several limitations. First, we were not able to demonstrate that some healthy residual corneal tissues were spared during chemical burning. Second, we were also unable to obtain complete corneal tissue thickness measurements before surgery. Given the severity of the original injury, it seems also surprising that limbal stem cell deficiency did not occur. It is hard to imagine how the limbus escaped significant injury, while the whole thickness of the stroma was destroyed. Both transient and limited limbal ischemia occurred soon after the injury but recovered in the ensuing days. ${ }^{1}$ Surviving limbal stem cells are capable to recover, 
multiply, and repopulate the area. Whether multiple layers of amnion transplantation in combination with the conjunctival flap might be able to provide a scaffold for the formation of corneal stroma, or for migration and repopulation with derived keratocytes, cannot be determined at this stage.

\section{Conclusion}

This case report describes an unusual event, in which a full-thickness regeneration occurred after extensive corneal burning. Any evidence of the hypothesized regenerative properties of human corneal stroma during corneal wound healing would have vast and impressive implications and justifies future studies.

\section{Author contributions}

All authors contributed toward design and conduct of the study, collection, management, analysis, and interpretation of data, preparation, drafting, review, and revision of the paper, gave final approval of the version to be published, and agree to be accountable for all aspects of the work.

\section{Disclosure}

The authors report no conflicts of interest in this work.

\section{References}

1. Dua HS, King AJ, Joseph A. A new classification of ocular surface burns. Br J Ophthalmol. 2001;85:1379-1383.

2. Hanada K, Shimazaki J, Shimmura S, Tsubota K. Multilayered amniotic membrane transplantation for severe ulceration of the cornea and sclera. Am J Ophthalmol. 2001;131:324-331.

3. Gundersen T, Pearlson HR. Conjunctival flaps for corneal disease: their usefulness and complications. Trans Am Ophthalmol Soc. 1969;67:78-95.

4. Kenyon KR, Tseng SC. Limbal autograft transplantation for ocular surface disorders. Ophthalmology. 1989;96:709-723.

5. Tsubota K, Toda I, Saito H, Shinozaki N, Shimazaki J. Reconstruction of the corneal epithelium by limbal allograft transplantation for severe ocular surface disorders. Ophthalmology. 1995;102:1486-1496.

6. Pinnamaneni N, Funderburgh JL. Concise review: stem cells in the corneal stroma. Stem Cells. 2012;30:1059-1063.

7. Acosta AC, Espana EM, Stoiber J, et al. Corneal stroma regeneration in felines after supradescemetic keratoprosthesis implantation. Cornea. 2006;25:830-838.
International Medical Case Reports Journal

\section{Publish your work in this journal}

The International Medical Case Reports Journal is an international, peer-reviewed open-access journal publishing original case reports from all medical specialties. Previously unpublished medical posters are also accepted relating to any area of clinical or preclinical science. Submissions should not normally exceed 2,000 words or

\section{Dovepress}

4 published pages including figures, diagrams and references. The manuscript management system is completely online and includes a very quick and fair peer-review system, which is all easy to use. Visit http://www.dovepress.com/testimonials.php to read real quotes from published authors. 